\title{
Anodic Polarization Behavior of Iron-Silicon Alloys*
}

\author{
By Masami Onishi** and Hiroyasu Mitani***
}

\begin{abstract}
Seven iron-silicon alloys having various silicon contents up to about $14 \%$ were polarized in $2 \mathrm{~N}_{2} \mathrm{SO}_{4}$. The relationship between silicon contents in the alloys and various properties such as the maximum or the limitting current density and the passive potential and the passive current density were investigated. $14 \%$ silicon alloy is much easier to passivate than iron, because the maxmum current density of the $14 \%$ alloy is equivalent to one-hundredth as large as that of iron and the passivation potential of the $14 \%$ alloy is close to its corrosion potential. An unusual variation in the passive current density with silicon content was observed; the passive current density increased with increasing Si content up to 6\%, but decreased with increasing $\mathrm{Si}$ content above $6 \%$.

The anodic polarization measurements were also carried out in 1 and $0.5 \mathrm{~N} \mathrm{H}_{2} \mathrm{SO}_{4}$ with three iron specimens, 6 and $14 \%$ Si. The polarization behavior of the $6 \%$ alloy was only affeted by the sulphuric acid concentration. In 1 and $0.5 \mathrm{~N} \mathrm{H}_{2} \mathrm{SO}_{4}$, the transition region from the active to passive state of the $6 \%$ alloy extended to the noble potential side accompanying a violent current oscillation. Such passivation phenomena can be explained to some extent on the basis of the silica formation on the anode surface. (Received October 27, 1969)
\end{abstract}

\section{Introduction}

Iron-silicon alloys containing about $14 \%$ silicon have excellent resistance to both oxidizing and non-oxidizing acids. For this reason, high silicon cast iron has been practically used as a corrosion resistant material to acids.

In order to make clear the corrosion mechanism of the alloy in acids, the anodic polarization behavior should be investigated at first. Although several authors ascribed the excellent corrosion resistance of the iron-silicon alloys to the protective effect of the silica film $^{(1)(2)}$, little has been known about the anodic behavior of the alloys which has been reported.

The purpose of this study is to investigate the anodic behavior of the iron-silicon alloys containing silicon less than about $14 \%$ in a dilute sulphuric acid solution in relation to passivation behavior of the alloys. The role of silica film in the anodic behavior was also discussed.

\section{Experimental Procedure}

Seven iron-silicon alloys containing various silicon contents up to about $14 \%$ were prepared by means of silicon impregnation (so-called siliconizing) and subsequent diffusion annealing as reported in a previous paper ${ }^{(3)}$.

Commercial electrolytic iron was melted in vacuum with a high frequency furnace and casted to a $2 \mathrm{~kg}$ ingot. The ingot was forged and rolled to a sheet $1.5 \mathrm{~mm}$ in thickness. The iron sheet was cut out to disks with diameter of $24 \mathrm{~mm}$. The iron disks were employed for the siliconizing and subsequent diffusion annealing.

* This paper was published in Japanese in the Journal of the Metal Finishing Society of Japan, 18(1967), 225;19(1968), 441.

** Department of Metallurgy, Faculty of Engineering, Osaka University, Suita, Osaka. Present address : Department of Metallurgy, Kyushu Institute of Technology, Kitakyushu, Japan.

*** Department of Metallurgy, Faculty of Engineering, Osaka University, Suita, Osaka, Japan.

(1) H. H. Uhlig, Suita, ed. : Corrosion Handbook, John Wiley and Sons, N.Y., (1963), p. 201.

(2) L. L. Shreir, ed. : Corrosion, Vol. 1, George Newnes Ltd., London, (1965), p. 3,98.

(3) H. Mitani and M. Onishi : J. Japan Inst. Metals, 30 (1966), 56.
The apparatus for the siliconizing treatment is shown in Fig. 1. Oxigen-free argon containing $10 \mathrm{vol} \%$ silicon tetra-chloride was passed through the reaction pipe at a flow rate of $30 \mathrm{~mL} / \mathrm{min}$.

Table 1 shows the conditions for the preparation of the iron-silicon alloys. In the colums of the siliconizing time

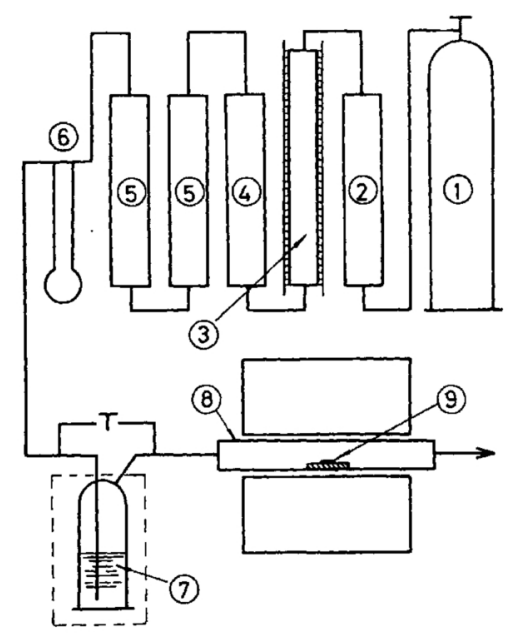

Fig. 1 Siliconizing apparatus
(1) Argon gas
(6) Flow meter
(2) $\mathrm{KOH}$
(3) Active copper
(4.) Silica gel
(7) $\mathrm{SiCl}_{4}$
(5) $\mathrm{P}_{2} \mathrm{O}_{5}$
(8) Reaction tube
(9) Specimen

Table 1 Conditions for preparation of the iron-silicon alloys containing various silicon contents

\begin{tabular}{|c|c|c|c|c|c|}
\hline \multirow[b]{2}{*}{ Specimen } & \multicolumn{2}{|c|}{ Siliconizing } & \multicolumn{2}{|c|}{ Heating } & \multirow{2}{*}{$\begin{array}{c}\text { Silicon } \\
\text { content } \\
(\%)\end{array}$} \\
\hline & $\begin{array}{c}\text { Temp. } \\
\left({ }^{\circ} \mathrm{C}\right)\end{array}$ & $\begin{array}{l}\text { Time } \\
(\min )\end{array}$ & $\begin{array}{c}\text { Temp. } \\
\left({ }^{\circ} \mathrm{C}\right)\end{array}$ & Time $(\mathrm{hr})$ & \\
\hline iron & - & - & 1235 & 0.5 & 0.0 \\
\hline $\begin{array}{l}3 \% \mathrm{Si} \\
6 \% \mathrm{Si} \\
9 \% \mathrm{Si}\end{array}$ & $\begin{array}{l}1235 \\
1235 \\
1235\end{array}$ & $\begin{array}{l}15 \times 2 \\
30 \times 2 \\
30 \times 3\end{array}$ & $\begin{array}{l}1235 \\
1235 \\
1235\end{array}$ & $\left.\begin{array}{l}20 \\
20 \\
20 \times 2\end{array}\right\}$ Dif- & $\begin{array}{l}2.9 \\
6.3 \\
9.3\end{array}$ \\
\hline $\begin{array}{l}11 \% \mathrm{Si} \\
13 \% \mathrm{Si}\end{array}$ & $\begin{array}{l}1235 \\
1235\end{array}$ & $\begin{array}{l}30+40 \\
30+45\end{array}$ & $\begin{array}{l}1350 \\
1350\end{array}$ & $\left.\begin{array}{l}1 \\
1\end{array}\right\}$ Melting & $\begin{array}{l}10.6 \\
13.0\end{array}$ \\
\hline $14 \% \mathrm{Si}$ & 1235 & 30 & - & - & 14.4 \\
\hline
\end{tabular}

1970 Vol. 11 
and the diffusion annealing time, the number which follows a cross sign denotes the number of the treatments. For the preparation of the $6 \%$ silicon alloy, for example, one side of the iron disk was siliconized for $30 \mathrm{~min}$, and then the other side, for $30 \mathrm{~min}$. After removing the circumferential edge of the siliconized disk by grinding, the diffusion annealing was carried out in argon atmosphere for homogenization. In order to prepare the $9 \%$ silicon alloy, the $6 \%$ silicon alloy was siliconized for $30 \mathrm{~min}$ again. By repeating the cutting and the diffusion annealing, a $9 \%$ silicon alloy was obtained.

A different method was used to prepare the iron-silicon alloys containing more than $10 \%$ silicon, because it was considerably time consuming to obtain a high silicon alloy by the above method. For the preparation of the 11 and $13 \%$ silicon alloys, each side of the iron disk was siliconized for the times shown on both sides of the plus sign in Table 1, and then the siliconized disk was kept for $1 \mathrm{hr}$ at a temperature near the melting point. In this case, the alloy specimens obtained were button-shaped.

When the iron disk was siliconized for $30 \mathrm{~min}$ at $1230^{\circ} \mathrm{C}$ the disk was coated with a $0.3 \mathrm{~mm}$ thick ferro-silicon film with nearly constant $14.4 \%$ silicon. The specimen thus obtained, was employed as the $14 \%$ silicon alloy.

Pure silicon (polycrystalline, 99.9999\%), fayalite $\mathrm{Fe}_{2} \mathrm{SiO}_{4}$ and a sintered iron-silica powder compact were used in this experiment.

Fayalite: Höganäs iron, hematite $\mathrm{Fe}_{2} \mathrm{O}_{3}$ and silica $\mathrm{SiO}_{2}$ powder were mixed to form the stoichiometric composition of $\mathrm{Fe}_{2} \mathrm{SiO}_{4}$. The mixture was cold pressed at $3 \mathrm{t} / \mathrm{cm}^{2}$ and fused in the flow of argon gas at $1250^{\circ} \mathrm{C}$.

Sintered iron-silica powder compact: a known mixture of Höganäs iron and silica powder was cold p:essed at 3 $\mathrm{t} / \mathrm{cm}^{2}$ and sintered in the flow of argon gas at $1050^{\circ} \mathrm{C}$ for $2 \mathrm{hr}$. The sintered compact was pickled in molten paraffin wax to avoid the penetration of sulphuric acid solution.

All the specimens were abraded with $0 / 3$ emery paper, degreased with acetone and then coated with Dekhotinsky cement, allowing an area of $0.25 \mathrm{~cm}^{2}$ to be exposed to sulphuric acid solution.

Dilute sulphric acid solution was prepared from a pure reagent and distilled water. Nitrogen gas, purified by a succesive passage through the active copper tower and an acid chromus chloride solution, was bubbled vigorously into the solution for $2 \mathrm{hr}$ to deaerate the solution. Fig. 2 shows the polarization cell used. The solution was thermostatically controlled at $25 \pm 0.1^{\circ} \mathrm{C}$.

All polarization measurements were conducted using a potentiostat with the capacity of $100 \mathrm{~mA}$ and the response of $10^{-1}$ sec. A saturated calomel electrode and a $1 \mathrm{~N}$ $\mathrm{H}_{2} \mathrm{SO}_{4}$ mercurous sulphate electrode were used as the reference electrodes. After immersion for $20 \mathrm{~min}$, the corrosion potential was determined and then polarization measurements were carried out. In case of necessity, cathodic polarization with a constant current density of $10 \mathrm{~mA} / \mathrm{cm}^{2}$ was conducted for ten $\mathrm{min}$ in order to obtain the oxide-free surface. After completion of the cathodic polarization, the polarization to a noble side started from the potential required to give the current density mentioned above. While increasing the potential at intervals of
$20 \mathrm{mV}$, the current was determined af ter the lapse of one min at each increment. In the present paper the potential was represented by the standard hydrogen scale and the current density was calculated on the basis of the geometric area of the specimen.

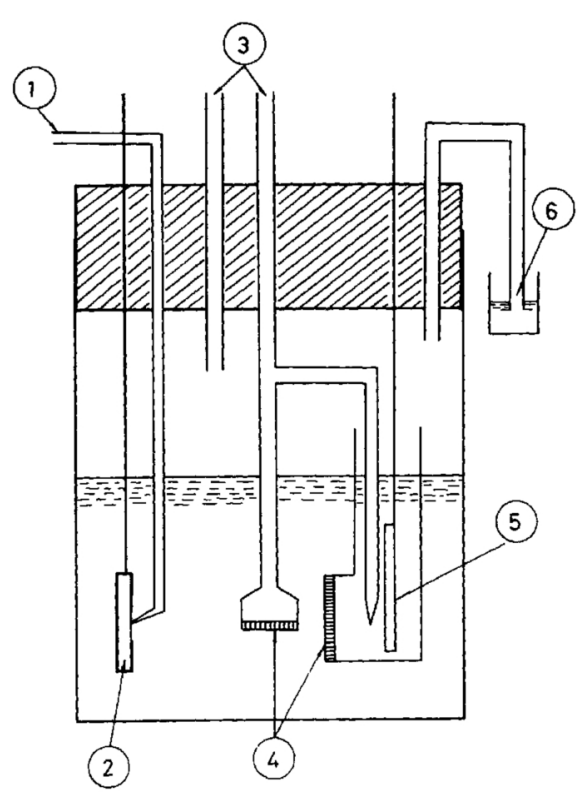

Fig. 2 Polarization cell

(1) To the reference electrode

(2) Anode specimen

(3) Nitrogen gas inlet

(4.) Sintered glass

(5) Plutinum auxiliary electrode

(6) Nitrogen gas outlet

\section{Results and Discussion}

\section{Anodic behavior of iron-silicon alloys in $2 \mathrm{~N} \mathrm{H}_{2} \mathrm{SO}_{4}$}

No notable relationship between the corrosion potential and the silicon content was observed as shown in Fig. 3. Fig. 4 shows the anodic polarization curves for seven ironsilicon alloys. Each polarization curve for the iron specimen and for the 3 and $6 \%$ silicon alloys has two current peaks and a violent oscillation region of the current which appears just after the second peak. The alloys containing 9 and $10 \%$ silicon passivate without the current oscillation, although these alloys also have two current peaks respectively. In each polarization curve for the 13 and 14\% silicon alloys there is only one peak having a very low current value. All of the electrodes in the passive state begin to evolve oxygen gas at the potentials between 1.75 and $2.0 \mathrm{~V}$. Further polarization above the oxygen evolution potential, however, does not give rise to the

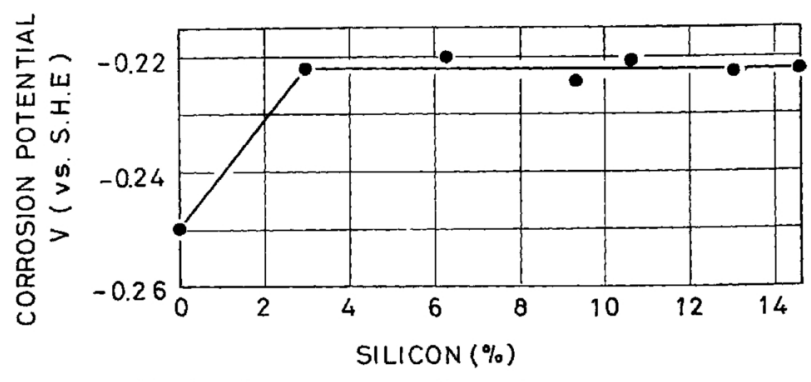

Fig. 3 Corrosion potential vs. silicon content 


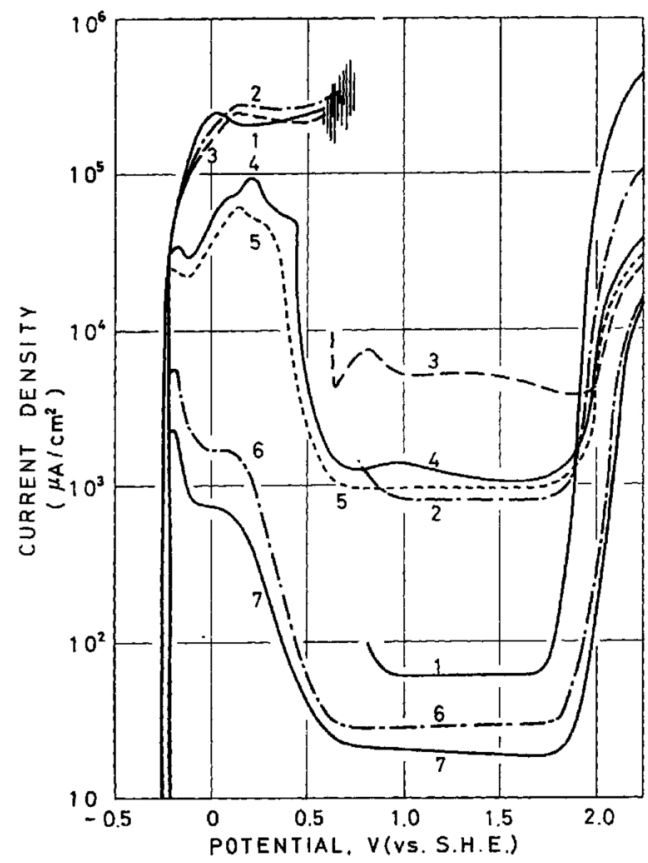

Fig. 4 Anodic polarization curves for seven iron-silicon alloys in $2 \mathrm{Na}_{2} \mathrm{SO}_{4}$. (1) iron (2) $3 \% \mathrm{Si}(3) 6 \% \mathrm{Si}$ $\begin{array}{llll}\text { (4) } 9 \% \mathrm{Si} & \text { (5) } 11 \% \mathrm{Si} & \text { (6) } 13 \% \mathrm{Si} & \text { (7) } 14 \% \mathrm{Si}\end{array}$

transpassive state as seen in the iron-chromium system $^{(4)}$ (5) and the iron-nickel ${ }^{(6)}$ system.

When two current peaks appeared, the current density at the second peak was chosen as the maximum current density. Variations in the maximum current density and in the potential corresponding to the maximum current density with silicon content are shown in the upper and lower parts of Fig. 5, respectively. Both of the maximum current density and the corresponding potential are nearly constant in the composition range of 0 to $6 \%$ silicon, beyond which, the values decrease with increasing $\mathrm{Si}$ content. For the 14\% silicon alloy the maximum current density is about one-hundredth of that for the iron speci-

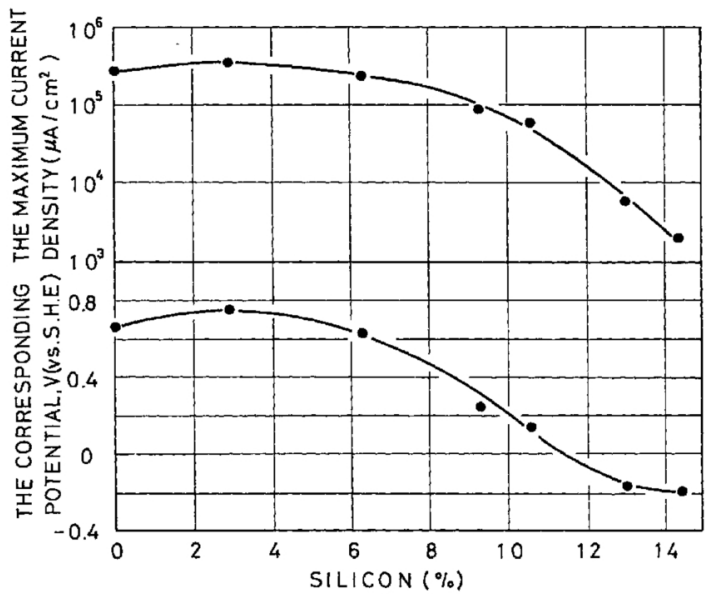

Fig. 5 The maximum current density and the corresponding potential vs. silicon content

(4) K. Shiobara, Y. Sawada and S. Morioka : Trans. JM, 6 (1965), 58.

(5) R. Oliver : Int. Ctte. Electrochem., Thermodynamics and Kinetics, 6 th Meeting, (1955).

(6) K. Shiobara, Y. Sawada and S. Morioka : J. Japan Inst. Metals, 28 (1964), 1. men and the corresponding potential approaches the corrosion potential.

The maximum current density and the corresponding potential were often defined as the passivation ${ }^{(4)}$ or the limitting ${ }^{(7)(8)}$ current density and the passivation potential $^{(4)(8)}$, respectively. The decrement of the passivation current and the approach of the passivation potential to the corrosion potential give rise to easy passivation. It can be thought, that the $14 \%$ silicon alloy passivates much easier than the iron specimen. This should be one of the reasons that the $14 \%$ silicon alloy has excellent resistance to corrosion.

The passive current density, which is regarded as the maximum current density required to maintain passivity, was evaluated at $1.25 \mathrm{~V}$ corresponding to the middle potential in the passive region. As shown in Fig. 6, the passive current density increases with increasing silicon content up to $6 \%$. For the alloys containing more than $6 \%$ silicon, the passive current density decreases with increasing silicon content and becomes less than that for iron at more than $13 \%$ silicon. The passive current density for the $6 \%$ silicon alloy is equivalent to about one hundred times greater than that for the iron specimen. This phenomenon suggests that the passive state of the $6 \%$ silicon alloy is extremely unstable.

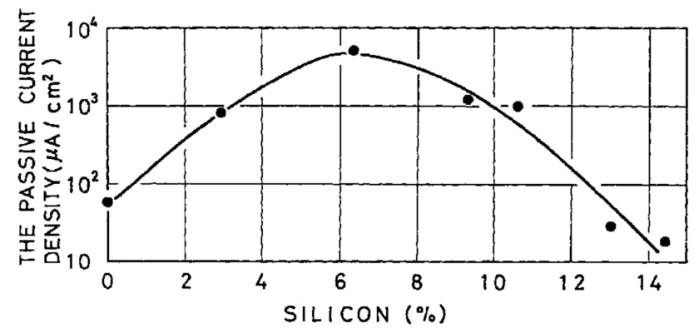

Fig. 6 The passive current density vs. silicon content

Observation of the exposed anode surfaces during the polarization measurements indicated that the anodes except for the $6 \%$ silicon alloy had almost the same appearance as that just after the immersion. When the $6 \%$ silicon alloy was polarized at the potential nobler than $0 \mathrm{~V}$ corresponding: to the first peak, this anode surface was surrounded by a white corrosion product which successively moved into the solution by the violent anodic dissolution of the alloy.

\section{Anodic behavior of iron-silicon alloys in 1 and $0.5 \mathrm{~N} \mathrm{H}_{2} \mathrm{SO}_{4}$}

The iron specimens and the 6 and $14 \%$ silicon alloys were polarized in 1 and $0.5 \mathrm{~N} \mathrm{H}_{2} \mathrm{SO}_{4}$. The anodic behavior of the $6 \%$ silicon alloy is only affected by the sulphuric acid concentration. In $\mathrm{I}$ and $0.5 \mathrm{~N} \mathrm{H}_{2} \mathrm{SO}_{4}$, the region of the current oscillation for the polarization curve of the $6 \%$ silicon alloy is extremely extended to the nobler side as shown in Fig. 7. Since the increase of $\mathrm{pH}$ has an effect of shifting the entire polarization curve to a more active side, the increase of $\mathrm{pH}$ by the dilution must be irrelevant to the extention. For the purpose of examining the effect of the sulphate ion concentration on the anodic

(7) M. Pražák und V. Č́hal : Corr. Sci., 2 (1962), 71.

(8) N.D. Tomashov : Corr. Sci., 4 (1964), 315. 
behavior of the $6 \%$ silicon alloy, the polarization measurement was conducted in a solution which was adjusted to have the same sulphate ion concentration as that in $2 \mathrm{~N}$ $\mathrm{H}_{2} \mathrm{SO}_{4}$ by the addition of $\mathrm{Na}_{2} \mathrm{SO}_{4}$ to $1 \mathrm{~N} \mathrm{H}_{2} \mathrm{SO}_{4}$. The result is shown in Fig. 8 in comparison with the polarization curves for 1 and $2 \mathrm{~N} \mathrm{H}_{2} \mathrm{SO}_{4}$. In each polarization curve for $2 \mathrm{~N} \mathrm{H}_{2} \mathrm{SO}_{4}$ and for $\mathrm{Na}_{2} \mathrm{SO}_{4}+1 \mathrm{~N} \mathrm{H}_{2} \mathrm{SO}_{4}$, the current oscillation ceases at $0.56 \mathrm{~V}$.

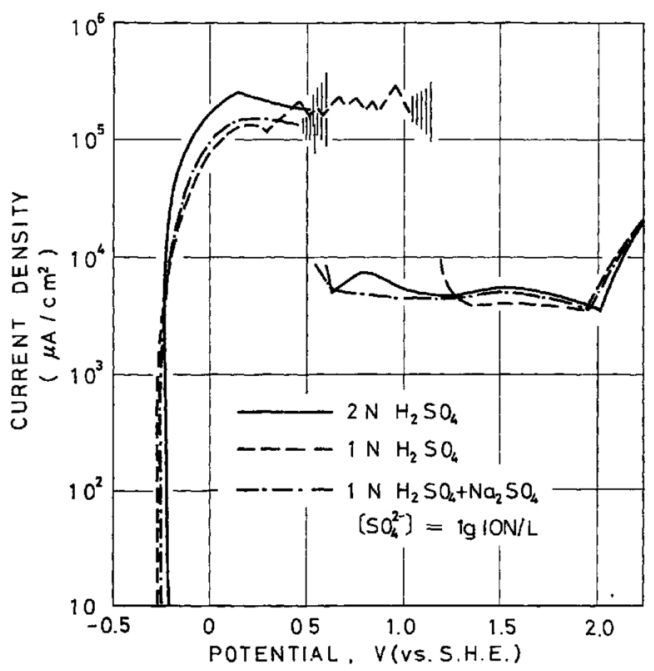

Fig. 7 Anodic polarization curves for the $6 \%$ silicon alloy in 2,1 and $0.5 \mathrm{~N} \mathrm{H}_{2} \mathrm{SO}_{4}$

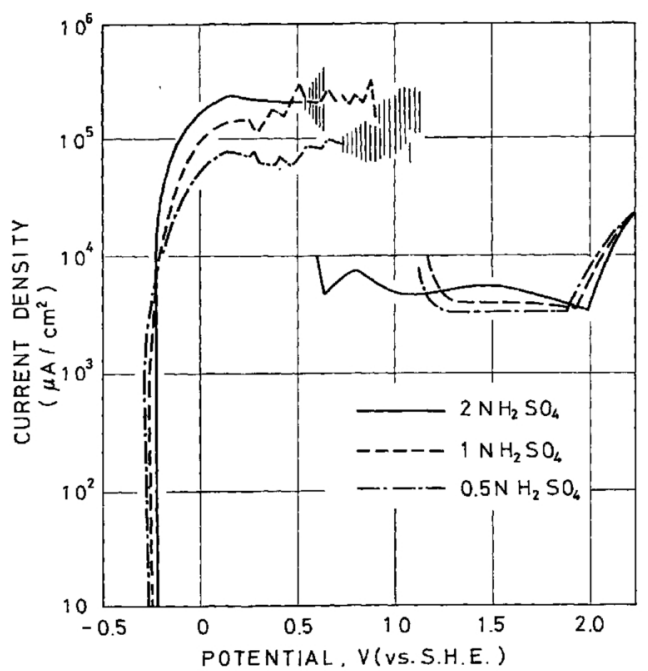

Fig. 8 Anodic polarization curves for the 6\% silicon alloy in 2 and $1 \mathrm{NH}_{2} \mathrm{SO}_{4}$, and in $0.5,1 \mathrm{NH}_{2} \mathrm{SO}_{4}+\mathrm{Na}_{2} \mathrm{SO}_{4}$

Morioka and Sakiyama ${ }^{(9)}$ observed that the passivation potential of iron in $0.4 \mathrm{~N} \mathrm{H}_{2} \mathrm{SO}_{4}$ shifted to a more noble side than that in $2 \mathrm{~N} \mathrm{H}_{2} \mathrm{SO}_{4}$. One of them investigated this phenomenon as a function of sulphate ion concentration in detail, and reported that the sulphate ion facilitated the anodic passivation of iron ${ }^{(10)}$. From these results and the fact that the passivation of the $6 \%$ silicon alloy delays even in $1 \mathrm{~N} \mathrm{H}_{2} \mathrm{SO}_{4}$, it may be considered that the

(9) S. Morioka and K. Sakiyama : J. Japan Inst. Metals, 18(1954), 643.

(10) K. Shiobara, Y.Sawada and S. Morioka : J. Japan Inst. Metals, 28 (1964), 6.
$6 \%$ silicon alloy is more difficult to passivate than iron.

The exposed surface of the $6 \%$ silicon alloy during the polarization measurement in $1 \mathrm{~N} \mathrm{H}_{2} \mathrm{SO}_{4}$ was surrounded by the white corrosion product in the same manner as mentioned previously. The amount of the product gathered from the solution after the polarization measurement was too small to be analyzed. To obtain a sufficient amount of the product for X-ray analysis, the $6 \%$ silicon alloy was kept at the potential of $0 \mathrm{~V}$ for $50 \mathrm{hr}$. $0.1 \mathrm{~g}$ of the product thus obtained was washed with water, dried in a desicator at room temperature, and then subjected to X-ray analysis. As shown in Fig. 9, the diffraction pattern indicates that the product is quartz, but it should be called silica because the product in the solution might exist in the form of a hydrate.

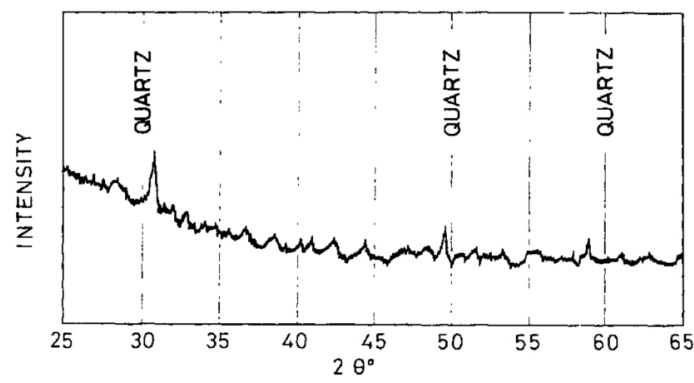

Fig. $9 \mathrm{X}$-ray diffraction pattern of the white product ( $\mathrm{CoK}_{\alpha}, \mathrm{Fe}$ filter)

\section{Anodic behavior of pure silicon and fayalite electrodes in $1 \mathrm{~N} \mathrm{H}_{2} \mathrm{SO}_{4}$}

The polarization curves for pure silicon and fayalite electrodes in $1 \mathrm{~N} \mathrm{H}_{2} \mathrm{SO}_{4}$ are shown in Fig. 10 in comparison with the curves for the iron specimen, and the alloys containing 6 and 14\% silicon. Polarity of four electrodes except for fayalite changed at $-0.25 \mathrm{~V}$, because these electrodes were polarized from the cathodic to the anodic region after the cathodic cleaning. The anodic current for the pure silicon reaches the satulating value at $-0.2 \mathrm{~V}$. At this potential, the curves for the 6 and $14 \%$ silicon alloys begin to deviate in the noble direction from the curve for the iron electrode.

According to a potential-pH diagram of silicon(11), silicon is a powerful reduction agent. It decomposes water with the evolution of hydrogen and gaseous silicon hydride $\mathrm{SiH}_{4}$, and forms silica and silicate at a more active potential than the potential investigated here. In most cases, however, the high reactivity of silicon does not of ten appear at room temperature. This is probably because of the remarkable irreversibility of the oxidation reduction reaction of silicon and passivation of silicon by the formation of a silica film ${ }^{(11)}$. If the potential and the process of the silica formation are not strictly considered, it is reasonable to consider that the pure silicon electrode was passivated by the formation of a silica film at $-0.2 \mathrm{~V}$ in Fig. 10. The deviation of the curves for the 6 and $14 \%$ silicon alloys from that for the iron specimen at $-0.2 \mathrm{~V}$ should be due to the silica formation in the same manner as in case of the pure silicon electrode.

(11) M. Pourbaix : Atlas of Electrochomical Equilibria in aqueous Solution, Pergamon Press, London, (1966), p. 459. 


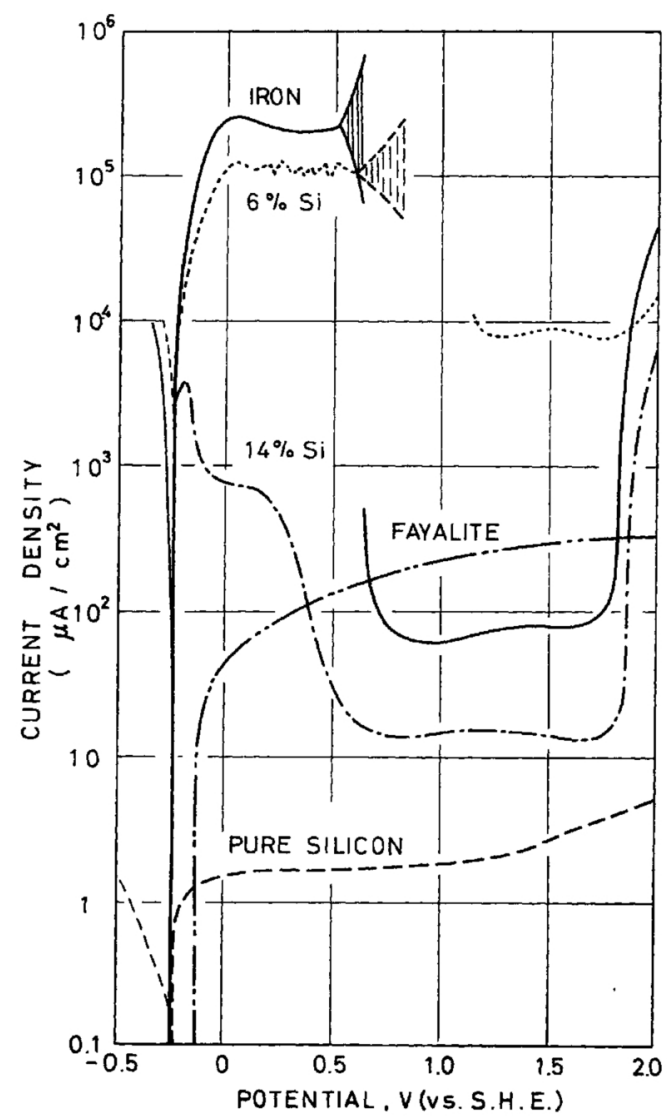

Fig. 10 Polarization curves for the iron, the 6 and 14\% silicon alloys, the pure silicon and the fayalite in $1 \mathrm{~N} \mathrm{H}_{2} \mathrm{SO}_{4}$

Nakajima and Maekawa ${ }^{(12)}$ reported that the first current peak in the anodic polarization curve for iron is caused by wüstite formation. If wüstite is formed on the surface of the iron-silicon alloy electrodes, fayalite might be produced by the reaction of wüstite with silica. However, as shown in Fig. 10, it is not valid to consider that fayalite governs the anodic behavior of iron-silicon alloys, because the behavior of fayalite is not similar to that of the iron-silicon alloys.

\section{Effect of the holding of a constant potential on the anodic behavior of iron-silicon alloys}

In order to obtain further information on the silica formation, the 6 and $14 \%$ silicon alloys were polarized in $1 \mathrm{~N} \mathrm{H}_{2} \mathrm{SO}_{4}$ again, and then held for $1 \mathrm{hr}$ at $-0.2 \mathrm{~V}$ corresponding to the potential at which the polarization curves for the alloys began to deviate from the curve of the iron specimen. The behavior of the $6 \%$ silicon alloy was not affected by the holding of the content potential, but for the $14 \%$ silicon alloy the anodic current density at $-0.2 \mathrm{~V}$ markedly decreased by the holding and the current density in the active region nobler than $-0.2 \mathrm{~V}$ decreased as shown in Fig. 11. These results show that the silica formed on the exposed surface of the $6 \%$ silicon alloy is successively released into the solution without its accumulation on the surface. On the contrary, for the $14 \%$ silicon alloy, it is reasonable to consider that the silica is accumulated during the holding intervals, resulting in the marked decrease of the current.

(12) N. Nakajima and T. Maekawa : Trans. JMM, 7 (1966), 280.

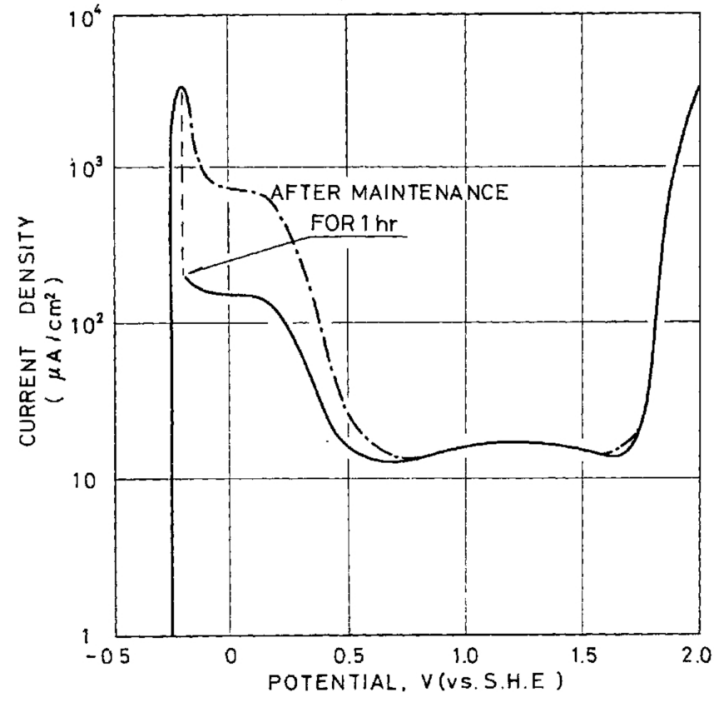

Fig. 11 Effect of the maintenance at $-0.2 \mathrm{~V}$ on the anodic polarization curve for the $14 \%$ silicon alloy in $1 \mathrm{~N} \mathrm{H}_{2} \mathrm{SO}_{4}$

\section{Flade potential of the iron-silicon alloys}

For obtaining the Flade potential of the iron specimen and the 6 and $14 \%$ silicon alloys, the current was cut off after each electrode was held for $1 \mathrm{hr}$ at $1.4 \mathrm{~V}$, and then the potential decay was traced by an automatic recorder. The arrest of the potential decay curve for the $6 \%$ silicon alloy was difficult to record because of the very brief decay of potential. Both of the decay curves for the iron specimen and the $14 \%$ silicon alloy arrested at $0.55 \mathrm{~V}$ as shown in Fig. 12. Since the $\mathrm{pH}$ of $1 \mathrm{~N}$ $\mathrm{N}_{2} \mathrm{SO}_{4}$ is about 0.6 , the above arrest potential agrees with the Flade potential which is represented by Frank's equation of $E_{F}=0.56-0.059 \mathrm{pH}^{(13)}$.

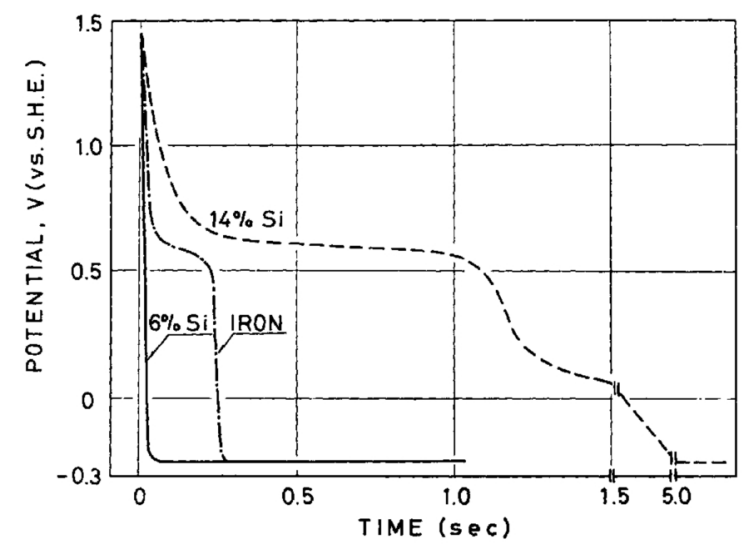

Fig. 12 Potential decay curves for the iron, the 6 and $14 \%$ silicon alloys in $1 \mathrm{~N} \mathrm{H}_{2} \mathrm{SO}_{4}$

Because the Flade potential is the equilibrium activation potential of a passive metal, it should be identified with the equilibrium potential for the initiation of the passive film formation. The agreement of the Flade potential for the $14 \%$ silicon alloy with that for iron suggests that the composition of the passive film for the $14 \%$ silicon alloy is essentially the same as that for iron. It can be

(13) F. Flade : Z. Phys. Chem., 76 (1911), 513; U. F. Frank : Z. Naturforsch., 4 a(1949), 378. 
understood, therefore, that the passivation of the $14 \%$ silicon alloy is completed by the filling up the gaps of the silica layer previously formed in the active state with the passive film of iron.

\section{Anodic behavior of the sintered iron-silica powder compact}

Fig. 13 shows the anodic curve for the sintered compact in a mixing ratio of 8 parts $\mathrm{Fe}$ to 1 part $\mathrm{SiO}_{2}$ which corresponds to the composition of $6 \%$ silicon. The anodic behavior of the sintered compact indicates the same trend as that of the $6 \%$ silicon alloy; the passivation of the sintered compact in $1 \mathrm{~N}_{2} \mathrm{SO}_{4}$ becomes difficult as a result of the extention of the current oscillation region to the noble side. As a matter of course, it cannot be considered that both surfaces of the sintered compact and of the $6 \%$ silicon alloy are in the same condition. In each case, however, a fresh surface abruptly appears when silica departs from the surface under the successive anodic dissolution of the electrode. The current oscillation prior to the passivation indicates that the anode is in the transition range from the active to the passive state. Because the anode in the transition range is especially sensitive to the external and internal disturbances, the abrupt appearance of the fresh surface would cause the extention of the current oscillation region.

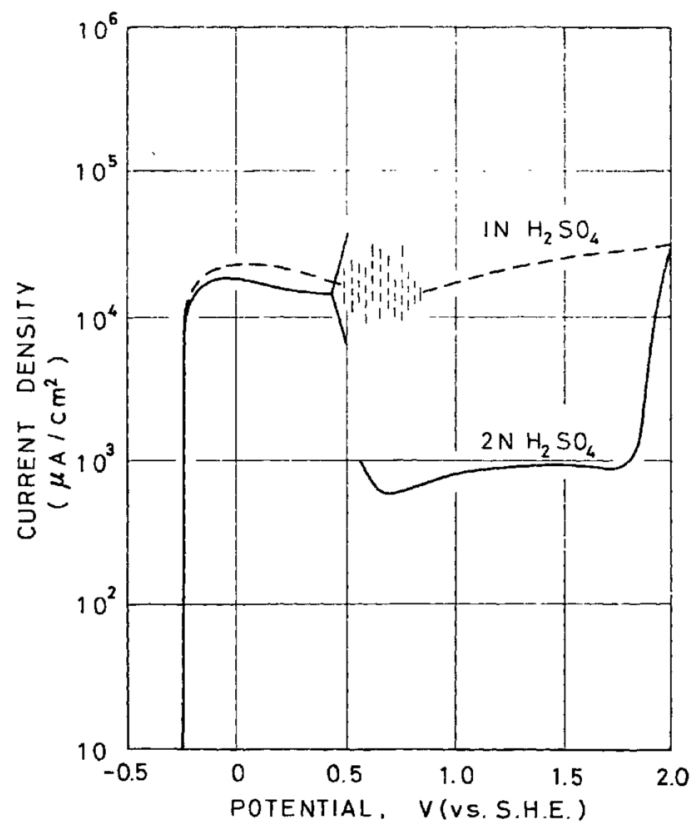

Fig. 13 Anodic polarization curves for the sintered ironsilica compact $\left(8 \mathrm{Fe}-1 \mathrm{SiO}_{2}\right)$ in 1 and $2 \mathrm{~N} \mathrm{H}_{2} \mathrm{SO}_{4}$

\section{Immersion tests in concentrated nitric acids}

All of the specimens were abraded with $0 / 3$ emery paper, degreased with acetone and then coated with Fullontex, allowing only an area of $1 \mathrm{~cm}^{2}$ to be exposed to nitric acid $\left(60 \sim 62 \% \mathrm{HNO}_{3}\right)$. Table 2 shows weight loss of the specimen after immersion for $30 \mathrm{~min}$ at $25^{\circ} \mathrm{C}$.
Corrosion loss of the $6 \%$ silicon alloy and the sintered compact is by far larger than that of the other specimens, and the $14 \%$ silicon alloy and pure silicon show a minimum corrosion loss. This trend is similar to the behavior of the passive current density shown in Fig. 6 .

Table 2 Corrosion loss of the specimens in concentrated $\mathrm{HNO}_{3}\left(25^{\circ} \mathrm{C}, 30 \mathrm{~min}\right.$ )

\begin{tabular}{c|c}
\hline Specimen & Corrosion loss $\left(\mathrm{mg} / \mathrm{cm}^{2}\right)$ \\
\hline iron & 53 \\
\hline $6 \%$ Si alloy & 148 \\
\hline $14 \%$ Si alloy & 23 \\
\hline pure silicon & 23 \\
\hline $8 \mathrm{Fe}-1 \mathrm{SiO}_{2}$ sintered compact & 108 \\
\hline
\end{tabular}

\section{Summary}

(1) Anodic polarization behavior of seven iron-silicon alloys containing less than about $14 \%$ silicon was investigated in $2 \mathrm{~N} \mathrm{H}_{2} \mathrm{SO}_{4}$. For the alloy with less than $6 \%$ silicon, both of the maximum current density and the potential corresponding to the maximum current density are constant independent of silicon content. For the composition of more than $6 \%$ silicon, however, the maximum current density increases with increasing silicon content and the corresponding potential approaches the active direction. For the 14\% silicon alloy, the maximun current density is very low and the corresponding potential is very close to the corrosion potential. Therefore, the $14 \%$ silicon alloy becomes easily passive. This may be a cause impart the $14 \%$ silicon alloy the excellent resistance to corrosion. The effect of the silicon content on the passive current density is quite different from the tendency mentioned above; the passive current density increases with increasing silicon content up to $6 \%$, but decreases with increasing silicon content above $6 \%$.

(2) The anodic polarization measurements of the iron specimen and the 6 and $14 \%$ silicon alloys were carried out in 1 and $0.5 \mathrm{~N} \mathrm{H}_{2} \mathrm{SO}_{4}$. The polarization behavior of the $6 \%$ silicon alloy is only affected by the sulphuric acid concentration. For the $6 \%$ silicon alloy in 1 and $0.5 \mathrm{~N} \mathrm{H}_{2} \mathrm{SO}_{4}$ the transition region from the active to passive state which accompanies a violent current oscillation extends to the noble potential side. This means that the $6 \%$ silicon alloy is difficult to passivate compared with iron. The successive departure of silica from the electrode surface in the transition state would cause the phenomenon mentioned above.

(3) From flade potential measurements it has been known that the composition of the passive film of the $14 \%$ silicon alloy is essentially the same as that of the iron specimen. It is reasonable to consider that the passivation of the $14 \%$ silicon alloy is completed by filling up the gaps of the silica film previously formed in the active state with the passive substance of iron. 